Canadian

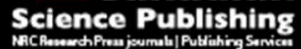

Canadian Journal of Physiology and Pharmacology Revue canadienne de physiologie et pharmacologie

\title{
Pinocembrin Attenuates Gentamicin-induced Nephrotoxicity in Rats
}

\begin{tabular}{|c|c|}
\hline Journal: & Canadian Journal of Physiology and Pharmacology \\
\hline Manuscript ID & cjpp-2015-0468.R1 \\
\hline Manuscript Type: & Article \\
\hline Date Submitted by the Author: & 07-Feb-2016 \\
\hline Complete List of Authors: & $\begin{array}{l}\text { Promsan, Sasivimon; University of Phayao, Division of Physiology, School } \\
\text { of Medical Sciences, } \\
\text { Jaikumkao, Krit ; Chiang Mai University, Department of Physiology, Faculty } \\
\text { of Medicine } \\
\text { Pongchaidecha, Anchalee ; Chiang Mai University, Department of } \\
\text { Physiology, Faculty of Medicine } \\
\text { Chattipakorn, Nipon ; Chiang Mai University, Cardiac Electrophysiology } \\
\text { Research and Training Center, Department of Physiology, Faculty of } \\
\text { Medicine, } \\
\text { Chatsudthipong, Varanuj ; Mahidol University, Department of Physiology, } \\
\text { Faculty of Science, } \\
\text { Arjinajarn, Phatchawan ; Chiang Mai University, Department of Biology, } \\
\text { Faculty of Science } \\
\text { Pompimon, Wilart ; Lampang Rajabhat University, Department of } \\
\text { Chemistry and Center of Excellence for Innovation in Chemistry, Faculty of } \\
\text { Science } \\
\text { Lungkaphin, Anusorn; Chiang Mai University, Physiology }\end{array}$ \\
\hline Keyword: & $\begin{array}{l}\text { Pinocembrin, Nephrotoxicity, Renal function, Organic anion transporter, } \\
\text { Gentamicin }\end{array}$ \\
\hline
\end{tabular}

\section{SCHOLARONE ${ }^{m}$ \\ Manuscripts}




\section{Pinocembrin Attenuates Gentamicin-induced Nephrotoxicity in Rats}

2 Sasivimon Promsan $^{\mathrm{a}}$, Krit Jaikumkao ${ }^{\mathrm{b}}$, Anchalee Pongchaidecha ${ }^{\mathrm{b}}$, Nipon Chattipakorn ${ }^{\mathrm{c}}$,

a Division of Physiology, School of Medical Sciences, University of Phayao, Phayao, Thailand

* Corresponding author: Anusorn Lungkaphin, Department of Physiology, Faculty of 


\section{ABSTRACT}

Oxidative stress-mediated apoptosis of renal tubular cells is a major pathology

3 of gentamicin-induced nephrotoxicity which is one of the prevailing causes of acute

4 renal failure. Pinocembrin is a major flavonoid found in rhizomes of fingerroot

5 (Boesenbergia pandurata). It has pharmacological and biological activities including

6 antimicrobial, anti-inflammatory, and antioxidant effects. Preclinical studies have

7 suggested that pinocembrin protects rat brain and heart against oxidation and apoptosis

8 induced by ischemia-reperfusion model. The aim of the current study was to investigate

9 the mechanisms of renoprotection elicited by pinocembrin in gentamicin-induced

10 nephrotoxicity. Nephrotoxic rats were induced by intraperitoneal injection (i.p) of

11 gentamicin and pinocembrin was administered via i.p. 30 min before gentamicin

12 treatment for 10 days. Gentamicin-induced nephrotoxicity was indicated by the reduced

13 renal function and renal Oat3 function and expression. Gentamicin treatment also

14 stimulated Nrf2, HO-1, and NQO1 and the pro-apoptotic protein, Bax and caspase-3,

15 concomitant with the attenuation of Bcl-XL expressions in the renal cortical tissues.

16 Pinocembrin pretreatment improved renal function, renal Oat3 function, reduced

17 oxidative stress and apoptotic conditions. These findings indicate that pinocembrin has

18 a protective effect against gentamicin-induced nephrotoxicity which may be due in part

19 to its antioxidant and anti-apoptotic effects, subsequently leading to improved renal

20 function.

22 Keywords: Pinocembrin; Nephrotoxicity; Renal function; Organic anion transporter;

23 Gentamicin; Oxidative stress; Apoptosis 


\section{Introduction}

3 bactericidal agent against severe gram-negative infections (Edson and Terrell 1999;

4 Noone et al. 1974). However, prolonged treatment of gentamicin produces serious side

5 effects such as nephrotoxicity and ototoxicity (Lopez-Novoa et al. 2011; Rizzi and

6 Hirose 2007). Gentamicin-induced renal toxicity is related to its preferential

7 accumulation in the renal proximal convoluted tubules (Abdel-Raheem et al. 2009),

8 leading to the damage of tubular epithelial cell, which further progresses to acute renal

9 failure (Nagai and Takano 2004). Although the mechanisms of gentamicin-induced

10 nephrotoxicity are not fully defined, the generation of reactive oxygen species (ROS),

11 mostly in the renal cortical mitochondria (Walker and Shah 1987; Yang et al. 1995),

12 induced vasoconstriction, mesangial cell contraction, cellular damage and necrosis via

13 lipid peroxidation, and these changes could be prevented or ameliorated by antioxidants

14 (Abdel-Raheem et al. 2009; Ajami et al. 2010; Mazzon et al. 2001; Nasri et al. 2013).

15 Nuclear factor E2-related factor-2 (Nrf2), a redox-sensitive transcription factor,

16 is a sensor of oxidative and electrophilic stress (Xing et al. 2012). In in vitro and in vivo

17 studies have shown that Nrf2 is essential for the antioxidant response element (ARE)-

18 mediated induction of several genes including phase II detoxifying enzymes such as

19 glutathione-S-transferase and quinine reductase (Kalayarasan et al. 2009). Nrf2 also

20 activates the antioxidant enzymes and many other proteins that detoxify xenobiotics and

21 neutralize ROS and/or reactive nitrogen species (RNS). In gentamicin-induced

22 ototoxicity, Nrf2 protected hair cell damage by activating Nrf2-mediated antioxidant

23 enzymes including NAD(P)H dehydrogenase quinine 1 (NQO1), GCLC (glutamate-

24 cysteine ligase catalytic subunit), SOD, and hemeoxygenase 1 (HO1) (Hoshino et al. 25 2011).

26 Organic anion transporter (Oat) plays a major role in the elimination of organic

27 anion substance. It is a family of solute carrier (SLC) transporter that is classified into

28 many types such as Oat1, Oat2, Oat3, Oat4, Oat5, Oat8, Oat9 and Oat10 (Koepsell

29 2013; Sekine et al. 2000). Oat3 shows the highest expression at basolateral membrane

30 of proximal tubule cell. An impaired renal excretion of various compounds along with 
1 down-regulation of Oat3 has been reported in gentamicin-induced acute renal failure

2 (Guo et al. 2013). However, the mechanisms of these alterations have not been clearly

3 elucidated.

4 Pinocembrin (5,7-dihydroxyflavonone, $\mathrm{C}_{15} \mathrm{H}_{12} \mathrm{O}_{4}$ ), a flavonoid found abundantly

5 in honeybee propolis (Bankova et al. 1982) and the rhizomes of Boesenbergia

6 pandurata (Punvittayagul et al. 2011), has several biological actions including anti-

7 microbial (Del Rayo Camacho et al. 1991; Pepeljnjak et al. 1985), antioxidant (Santos

8 et al. 1998), anti-inflammatory (Sala et al. 2003; Soromou et al. 2012), and vaso-

9 relaxation (Shi et al. 2011) effects. Recently, preclinical studies have suggested

10 pinocembrin attenuates cerebral ischemic injury in middle cerebral artery occlusion rats,

11 (Gao et al. 2008). Pinocembrin also reduced compensatory increase in superoxide

12 dismutase (SOD) activity, decreased in both malondialdehyde (MDA) content and

13 myeloperoxidase (MPO) activity in global cerebral ischemic/reperfusion (I/R) rat

14 models (Shi et al. 2011). It exhibited cardioprotective effects during $\mathrm{I} / \mathrm{R}$ by its

15 antioxidant and anti-apoptotic effects (Lungkaphin et al. 2015). These data led to

16 investigate the renoprotective effect of pinocembrin against gentamicin-induced

17 nephrotoxicity. We tested the hypothesis that the renoprotective mechanisms of

18 pinocembrin against gentamicin-induced nephrotoxicity due to its antioxidant and anti-

19 apoptotic effects.

\section{Materials and methods}

21 Chemicals and reagents

22 Gentamicin was acquired from The Govt. Pharm.Org (Bangkok, Thailand). The

23 pinocembrin compound (95\% purity) was isolated from the rhizomes of Boesenbergia

24 pandurata which was carried out at the Department of Chemistry and Center of

25 Excellence for Innovation in Chemistry, Faculty of Science, Lampang Rajabhat

26 University (Lampang, Thailand). Tween 80 was supplied by Calbiochem, Merck

27 Millipore (Billerica, MA, USA). Mammalian tissue lysis/extraction reagent was

28 provided by Sigma Chemical Co (MO, USA). Complete protease inhibitor cocktail was

29 acquired from Roche Applied Science (IN, USA). TBARS assay kit was purchased 
1 from Cayman Chemical (Ann Arbor, MI, USA). SOD activity assay kit was provided

2 by BioAssay Systems (CA, USA). BUN and creatinine assay kits were purchased from

3 DiaSys Diagnostic Systems GmbH (Holzheim, Germany). The radiolabeled estrone

4 sulfate $\left(\left[{ }^{3} \mathrm{H}\right] \mathrm{ES}\right)$ was purchased from PerkinElmer (TX, USA). Primary Oat3 antibody

5 was from Cosmo Bio Co. Ltd. (Tokyo, Japan). The $\mathrm{Na}^{+}-\mathrm{K}^{+}$-ATPase, caspase-3 and Bcl-

6 XL antibodies were acquired from Millipore (MA, USA). The primary anti-Heme

7 Oxygenase 1 (HO-1) and primary anti-NQO1 antibodies were from Abcam (MA,

8 USA). The primary PKC $\alpha$, NADPH oxidase (NOX4) and primary anti-Nrf2 antibodies

9 were from Santa Cruz Biotechnology (TX, USA). The primary anti-Bax, and $\beta$-actin

10 antibodies were from Cell Signaling Technology (MA, USA). The horseradish

11 peroxidase (HRP)-conjugated goat anti-rabbit or anti-mouse secondary antibody was

12 purchased from Amersham (IL, USA). A poly-vinylidene fluoride (PVDF) membrane

13 was provided by Millipore (MA, USA). The ECL enhanced chemiluminescence agent

14 and Hyperfilm were acquired from GE Healthcare (Buckinghamshire, UK).

\section{The method of pinocembrin preparation}

percolated with $n$-hexane at room temperature for 9 days. Subsequently, the residue was

18 percolated with ethyl acetate for 15 days. Then, the filtrate was evaporated to dryness

19 under low pressure to obtain anethyl acetate crude extract (79.99 g). To obtain

pinocembrin, the ethyl acetate extract was firstly subjected to coarse separation on a

silica column chromatography. Gradient elution was conducted initially with $n$-hexane, gradually enriched with ethyl acetate, followed by increasing amounts of methanol in ethyl acetate and finally with methanol. The obtained solid was recrystalized from ethanol to obtain pinocembrin (69.32 mg). Finally, structural confirmation was performed using UV, FTIR, $1 \mathrm{H}$ NMR, $13 \mathrm{C}$ NMR, MS. The purity of pinocembrin was more than 95\% (Charoensin et al. 2010).

Previous study investigated the toxicity dose of pinocembrin in a rat model

28 (Charoensin et al. 2010). Pinocembrin at the doses of $1-100 \mathrm{mg} / \mathrm{kg}$ and $500 \mathrm{mg} / \mathrm{kg}$ were

29 administrated by gavage feeding. There were neither toxic nor death in rats studied in 
1 that model. Recently, there was a report in a double-blind, placebo-controlled,

2 randomized study carried out in 58 healthy subjects (Cao et al. 2015). Single ascending

3 doses of pinocembrin $(20-150 \mathrm{mg})$ as well as multidose study at $60-\mathrm{mg}$ pinocembrin

4 were investigated. The results showed that pinocembrin was well tolerated and no

5 serious adverse events occurred. No subjects were discontinued because of a treatment

6 emergent AE. These findings indicated that there was no lethal or toxic dose of

7 pinocembrin.

8 Animals

9 Male Sprague-Dawley rats (240-250 g) from the National Laboratory Animal

10 Centre, Mahidol University, Salaya, Nakornpathom were housed in the animal room at

11 controlled temperatures in a 12:12 h light/dark cycle and fed with a normal pellet diet

12 and water ad libitum. This study was carried out in strict accordance with the

13 recommendations in the Guide for the Care and Use of Laboratory Animals of the

14 National Institutes of Health. The protocol was approved by the Committee on the

15 Ethics of Animal Experiments of the Faculty of Medicine, Chiang Mai University

16 (Permit Number: 13/2557). All surgery was performed under sodium pentobarbital

17 anesthesia, and all efforts were made to minimize suffering.

18 Experimental design

19 The rats were randomly divided into 5 groups (6 rats per group) and treated for 2010 days, as follows:- (1) Control group: the rats were injected intraperitoneally (i.p.)

21 with Tween 80, (2) Gentamicin group: the rats were treated (i.p.) with gentamicin at a

22 dose of $100 \mathrm{mg} / \mathrm{kg} / \mathrm{day}$, (3) Pinocembrin plus Gentamicin group: the rats were injected

23 (i.p.) with pinocembrin (dissolved in Tween 80 at a dose of $50 \mathrm{mg} / \mathrm{kg} / \mathrm{day}$, obtained

24 from air-dried finger-root weighing $140 \mathrm{~g}$ ) $30 \mathrm{~min}$ prior to the injection of gentamicin,

25 (4) Pinocembrin-50 group: the rats were injected i.p. with pinocembrin ( $50 \mathrm{mg} / \mathrm{kg} / \mathrm{day})$

26 for 10 days and (5) Pinocembrin-75 group: the rats were injected i.p. with pinocembrin

27 (75 mg/kg/day) for 10 days. The dose of pinocembrin used in this study was chosen

28 from our preliminary experiment and from a previous study (Soromou et al. 2012). 
After the treatment on $10^{\text {th }}$ day, the animals were placed into individual

3

4

\section{Determination of renal Oat3 function}

The uptake of radiolabeled estrone sulfate $\left(\left[{ }^{3} \mathrm{H}\right] \mathrm{ES}\right)$, a specific Oat3 substrate, into the renal cortical slice, which reflects the renal Oat3 function, was examined. After the animals were sacrificed, the kidneys were removed, decapsulated and placed in freshly oxygenated ice-cold modified Cross and Taggart saline buffer (containing the following: $95 \mathrm{mM} \mathrm{NaCl}, 80 \mathrm{mM}$ mannitol, $5 \mathrm{mM} \mathrm{KCl}, 0.74 \mathrm{mM} \mathrm{CaCl}_{2}$, and $9.5 \mathrm{mM}$ $\mathrm{Na}_{2} \mathrm{HPO}_{4}, \mathrm{pH}$ 7.4). Thin renal cortical slices ( $\leq 0.5 \mathrm{~mm} ; 5-15 \mathrm{mg} /$ slice, wet weight) were cut with a Stadie-Riggs microtome and were pre-incubated in modified Cross and Taggart buffer for $10 \mathrm{~min}$ then incubated in $1 \mathrm{~mL}$ of buffer containing $50 \mathrm{nM}\left[{ }^{3} \mathrm{H}\right] \mathrm{ES}$ for $30 \mathrm{~min}$ at room temperature. At the end of the uptake period, the slices were washed in $0.1 \mathrm{M} \mathrm{MgCl}_{2}$, blotted on filter paper, weighed, and dissolved in $0.5 \mathrm{~mL}$ of $1 \mathrm{M} \mathrm{NaOH}$ 
and then the preparation was neutralized with $0.5 \mathrm{~mL}$ of $1 \mathrm{~N} \mathrm{HCl}$. The radioactivity was measured using a liquid scintillation analyzer (PerkinElmer, MA, USA). The $\left[{ }^{3} \mathrm{H}\right] \mathrm{ES}$ uptake was calculated as tissue to medium (T/M) ratio (dpm/g tissue $\div \mathrm{dpm} / \mathrm{mL}$ medium).

\section{Tissue preparation for western blot analysis}

Renal cortical tissue, $0.1 \mathrm{~g}$, was chopped and homogenized on ice in Mammalian cell Lytic buffer with a protease inhibitor cocktail. Each cellular component, whole cell lysate, membrane, and cytosolic fraction, were prepared from renal cortical slices using differential centrifugation as previously described (Lungkaphin et al. 2014). Briefly, the homogenate was centrifuged at 5,000x g for 10 min at $4{ }^{\circ} \mathrm{C}$, the supernatant was designated as whole cell lysate, and then the supernatant was further centrifuged at $100,000 \mathrm{x}$ g for $2 \mathrm{~h}$ at $4{ }^{\circ} \mathrm{C}$ to obtain a membrane (pellet) and cytosolic (supernatant) fractions. The 5,000x g pellet was re-suspended and centrifuged at $10,000 \mathrm{xg} 4{ }^{\circ} \mathrm{C}$ for $10 \mathrm{~min}$. The supernatant fraction from the spin was designated as the nuclear fraction. All the fractions collected were stored at $-80{ }^{\circ} \mathrm{C}$ until use.

\section{Determination of renal Oat3 expression}

The total cell lysates and the membrane fractions from the renal cortex were subjected to SDS-PAGE, and subsequently transferred to a PVDF membrane, as described above. Primary Oat3 antibody at concentration of 1:500 was added. To confirm the enrichment of the membrane fraction, the $\mathrm{Na}^{+}-\mathrm{K}^{+}-\mathrm{ATPase}$ expression was determined as a membrane fraction marker. The density of the protein signal on Hyperfilm was analyzed using the histogram function of Adobe Photoshop CS5 (Adobe Corp., CA, USA) scanning. The protein level was normalized by $\beta$-actin as a loading control.

\section{Determination of renal lipid peroxidation}

In order to determine conditions of renal oxidative stress, the measurement of malondialdehyde (MDA) level, a marker of lipid peroxidation, in the renal cortical 
1 tissues was carried out. Briefly, the renal cortical tissues were cut and suspended in

2 CelLyticMT mammalian tissue lysis/extraction reagent containing a 1\% complete

3 protease inhibitor cocktail, made according to the manufacturer's protocol. The tissues

4 were then homogenized and centrifuged at $1,600 \mathrm{~g}$ for $10 \mathrm{~min}$ at $4{ }^{\circ} \mathrm{C}$. The supernatants

5 were collected for the determination of MDA concentration using a commercial

6 TBARS assay kit, as previously described (Ohkawa et al. 1979). Each sample was

7 expressed as total MDA level to total protein concentration (nmol/mg protein).

Determination of renal cortical superoxide dismutase (SOD) activity

The renal cortex tissue was homogenized at $5 \mathrm{~mL} / \mathrm{g}$ in cold lysis buffer $(50 \mathrm{mM}$

10 potassium phosphate, $0.1 \mathrm{mM}$ EDTA, $0.5 \%$ Triton X-100) and centrifuged at $12,000 \mathrm{~g}$

11 for $5 \mathrm{~min}$ at $4^{\circ} \mathrm{C}$. The supernatants were used for total SOD activity determination,

12 according to the manufacturer's protocol.

\section{Determination of renal oxidative stress and apoptosis}

The renal oxidative stress pathway and apoptosis protein markers were

15 determined by western blot analysis. The renal cortical fraction was used to determine

16 the protein expression of $\mathrm{PKC} \alpha, \mathrm{Nrf} 2$, heme oxygenase-1 (HO-1), NAD(P)H

17 dehydrogenase quinine 1 (NQO1), NADPH oxidase (NOX4), Bax, Bcl-XL and

18 caspase-3. The whole cell fraction was used to determine the PKC $\alpha, \mathrm{HO}-1$, NQO1,

19 NOX4, caspase-3 and the Bcl-2 protein family (pro-apoptotic; Bax and anti-apoptotic;

20 Bcl-XL proteins) expressions by western blot analysis as described above. Briefly, total

21 cell lysates, cytosolic, membrane and nuclear fractions from the renal cortex were

22 subjected to $10 \%$ SDS-polyacrylamide gel electrophoresis (SDS-PAGE), and

23 subsequently transferred to a poly-vinylidene fluoride (PVDF) membrane. The primary

24 PKC $\alpha$ antibody at concentration of 1:2,000, primary anti-Heme Oxygenase 1 (HO-1)

25 antibody at concentration of 1:2000, primary anti-NQO1 antibody at concentration of

26 1:500, primary anti-NOX4 antibody at concentration 1:500, primary anti-Bax at

27 concentration of 1:3000, Bcl-XL at concentration of 1:500 and caspase-3 at

28 concentration 1:250 were used to probe overnight at $4^{\circ} \mathrm{C}$. For determination of the Nrf2 
expression was performed using nucleus and cytosol fractions. Primary anti-Nrf2 antibody at concentration of 1:250 was added. The membranes were washed three times with TBST and incubated with horseradish peroxidase (HRP)-conjugated goat anti-

4 rabbit or anti-mouse secondary antibody at room temperature for $1 \mathrm{~h}$ and developed with an ECL enhanced chemiluminescence agent. Each membrane was stripped and re-

6 probed with mouse anti- $\beta$-actin antibody that served as a loading control or other

7 antibody for further detection of the interest protein expression. The densities of the

8 protein signals on the Hyperfilm were analyzed using the histogram function of Adobe

9 Photoshop CS5 (Adobe Corp., CA) scanning.

\section{Histopathological study}

11 The paraffin-embedded specimen was cut into $2 \mu$ m-thick sections, mounted on 12 microscope slides, and stained with hematoxylin and eosin (H\&E) for histological

13 assessment. The samples were examined under a light microscope for evaluation of

14 tubular and glomerular changes. Histopathological alteration or tubular damage was 15 assessed by the degree of tubular dilatation, necrosis, apoptosis and cast formation in 16 the renal tubular cells.

\section{Statistical analysis}

18 The data are expressed as mean \pm standard error of mean (S.E.M) and analyzed 19 using the SPSS version 17 statistical program (SPSS Inc., Chicago, IL, USA). One-way 20 analysis of variance (ANOVA), followed by the Newman-Keuls test, was performed. A $21 P$ value $<0.05$ was considered statistically significant.

\section{Results}

23 The effect of pinocembrin pretreatment on physiological and renal function parameters 24 in the gentamicin-induced nephrotoxicity

25 There was no difference in the mean initial body weight between the 26 experimental groups. After 10 day of treatment, the gentamicin-treated rats had 27 significantly lower body weights, and markedly higher kidney weight as well as higher 
1 kidney weight per body weight ratio than those of the control rats $(P<0.05)$ (Table 1).

2 Compared with the control group, the serum BUN and creatinine levels were

3 significantly higher $(P<0.05)$ while the $\mathrm{C}_{\mathrm{cr}}$ was markedly lower in the gentamicin

4 group $(P<0.05)$ indicating impaired renal function. Pinocembrin pretreatment (50 or 75

$5 \mathrm{mg} / \mathrm{kg}$ ) apparently increased the body weight and decreased the kidney weight and

6 kidney weight per body weight ratio $(P<0.05)$. The serum BUN and creatinine levels

7 were also significantly decreased $(P<0.05)$ although the $\mathrm{C}_{\mathrm{cr}}$ had a tendency to increase,

8 in gentamicin plus pinocembrin (50 or $75 \mathrm{mg} / \mathrm{kg}$ ) group compared with the gentamicin

9 group with pinocembrin. Since the pinocembrin at the doses of 50 and $75 \mathrm{mg} / \mathrm{kg}$

10 showed similar results, we selected to use pinocembrin at the low dose $(50 \mathrm{mg} / \mathrm{kg})$ for

11 the subsequent experiments.

12 The effect of pinocembrin pretreatment on renal Oat 3 function and expression in the 13 gentamicin-induced nephrotoxicity

14 A significant decrease in the $\left[{ }^{3} \mathrm{H}\right] \mathrm{ES}$ uptake into the renal cortical slides was

15 observed in the gentamicin-treated rats compared to that of the control rats $(P<0.05)$

16 (Fig. 1). Interestingly, pinocembrin pretreatment led to significantly improved the renal

17 Oat3 function as shown by an increase in the $\left[{ }^{3} \mathrm{H}\right] \mathrm{ES}$ uptake compared with the

18 gentamicin group $(P<0.05)$. To determine whether the decreased function of renal Oat3

19 in the gentamicin-treated rats was partly due to the down-regulated expression of Oat3

20 at the basolateral membrane, the Oat3 expression in the membrane and whole cell lysate

21 fractions of the renal cortex were determined by the western blot analysis. The

22 expression level of renal Oat3 from the whole cell lysate fraction was unchanged in all

23 the experimental groups (Fig. 2B). However, the membrane expression of Oat 3 in the

24 gentamicin-treated rats was significantly decreased when compared with the control

25 group $(P<0.05)$ (Fig. 2A). Pinocembrin pretreatment significantly attenuated a

26 decreased membrane expression of Oat3 when compared to the gentamicin-treated rats

$27(P<0.05)$. These results suggest that the decreased renal Oat3 function in the

28 gentamicin-treated rats may result from the down-regulation of Oat 3 at the membrane

29 of renal tubular cells. The reduced renal Oat 3 function and expression can be improved

30 by pinocembrin pretreatment in this study. 
1 The effect of pinocembrin pretreatment on oxidative stress conditions in the gentamicin-

2 induced nephrotoxicity

3 The renal cortical MDA was increased in the gentamicin-treated rats in relation

4 to that of the control rats $(P<0.05)$ (Fig. 3A). An apparent decrease of MDA to normal

5 level in the pinocembrin plus gentamicin group $(P<0.05)$ indicated that a marked

6 generation of oxidative stress by gentamicin is significantly prevented by pinocembrin

7 pretreatment. The result of SOD activity was consistent with the previous studies,

8 demonstrating that gentamicin-treated rats had significant decrease in the SOD activity

9 as compared with the control rats $(P<0.05)$ (Fig. 3B). Surprisingly, pinocembrin

10 pretreatment could not improve the activity of the SOD enzyme when compared with

11 the gentamicin-treated group.

12 The effect of pinocembrin pretreatment on the oxidative stress pathways in the 13 gentamicin-induced nephrotoxicity

14 Based on previous findings that PKC $\alpha$ was activated by the overproduction of

15 ROS, we determined whether an increased oxidative stress in the renal cortical tissue by

16 gentamicin could activate PKC $\alpha$. As shown in Fig. 4A, the gentamicin-treated rats

17 significantly enhanced PKC $\alpha$ expression when compared with the control rats $(P<$

18 0.05), and this increased PKC $\alpha$ expression was significantly reduced by pinocembrin

19 pretreatment $(P<0.05)$. These findings indicate that the overproduction of ROS in

20 gentamicin-treated rats activates $\mathrm{PKC} \alpha$ signaling pathways, and pinocembrin can

21 attenuate the production of ROS and consequently inactivate PKC $\alpha$. We found that

22 NOX4 expression was stimulated in gentamicin-treated rats $(P<0.05)$. The treatment

23 with pinocembrin could inhibit NOX4 expression as compared to the gentamicin-treated

24 rats $(P<0.05)$ (Fig. 4B).

$25 \mathrm{Nrf2}$, the transcription factor that promotes the antioxidant defense system or

26 protects against oxidative stress, has been shown to protect against gentamicin-induced

27 hair cell damage. Thus, we postulated that an increased oxidative stress in gentamicin-

28 treated rats may activate the Nrf2 and Nrf2-mediated antioxidant enzymes. As shown in

29 Fig. 5A and B, the Nrf2 expression in the nuclear fraction of the renal cortical tissue 
was significantly increased in the gentamicin-treated rats when compared with the control rats $(P<0.05)$. However, there was no change in the Nrf2 expression in the cytosol fraction between the experimental groups. These results suggest that the activation of Nrf2 leads to an increased translocation of Nrf2 from the cytoplasm to the nucleus in gentamicin-treated rats. Interestingly, the nuclear expression of Nrf2 was reduced $(P<0.05)$ in the pinocembrin plus gentamicin-treated rats compared to the gentamicin-treated rats. Additionally, the expressions of the antioxidant enzyme and the

8 detoxification gene, HO-1 and NQO1, respectively, were apparently increased $(P<$

90.05 ) in the gentamicin-treated rats as compared with the control rats (Fig. 5C and D).

10 Importantly, the increased HO-1 and NQO1 expressions were significantly reduced by

11 pinocembrin pretreatment $(P<0.05)$. These results suggest that pinocembrin

12 pretreatment can lessen the oxidative stress conditions induced by gentamicin through

13 the modulation of the antioxidant defense parameters.

14 The effect of pinocembrin on renal apoptosis in the gentamicin-induced nephrotoxicity

15 The gentamicin-treated rats demonstrated an increase in the expression of the pro16 apoptotic protein, Bax, along with a decreased expression of the anti-apoptotic protein, 17 Bcl-XL when compared with the control rats $(P<0.05)$ (Fig. 6A, B and C). Pinocembrin 18 pretreatment significantly reversed an altered expression of the apoptosis-related protein 19 in the gentamicin-treated rats $(P<0.05)$. We found that caspase-3 expression was 20 increased in the gentamicin-treated rats $(P<0.05)$. Pinocembrin treatment could reverse 21 this effect by reducing the level of caspase-3 as compared to the gentamicin-treated rats $22(P<0.05)$ (Fig. 6D).

23 The effect of pinocembrin on renal morphology in the gentamicin-induced 24 nephrotoxicity

25 The histological changes and the pathological manifestations of the kidney are 26 presented in Fig. 7. Normal kidney morphology was observed in the control (A) and the 27 pinocembrin (D) groups. Nephrotoxicity in the gentamicin-treated rats was evidenced 28 by tubular dilatation, tubular epithelial damage, intracellular cast formation, nuclear 
1 irregularity, karyorrhexis and inflammation (B); however, these defects were

2 ameliorated by pinocembrin pretreatment (C).

\section{Discussion}

4

The present study demonstrated that gentamicin treatment caused nephrotoxicity which was manifested by marked increases in serum BUN and creatinine with a decrease in $\mathrm{C}_{\mathrm{cr}}$. These findings were correlated with the histopathological damages of the kidney. The impaired renal function was accompanied with the reduced renal Oat3 function, an indicator of proximal tubular transport function. The down-regulation of renal Oat3 function and expression in gentamicin-treated rats was associated with the increases in oxidative stress and apoptosis. Pinocembrin pretreatment showed the marked decreases in ROS production and apoptosis leading to an improvement of renal function.

In this study, an elevation of renal cortical MDA level along with the decrease activity of SOD indicated the increased oxidative stress condition induced by gentamicin in rat kidneys. Several investigators have reported the relationship between free radical formation and gentamicin-induced acute renal injury (Karahan et al. 2005; Shin et al. 2014; Walker et al. 1999). The subsequent generation of reactive oxygen metabolites damages the protein molecules and degrades the membrane bound phospholipids through the process of lipid peroxidation (Sahu et al. 2013), which were correlated with the inactivation of antioxidant enzymes such as GSH-Px, CAT and SOD (Kang et al. 2013; Karahan et al. 2005). The decreased renal cortical SOD activity in gentamicin-treated rats implied the depletion of antioxidant enzymes during the combating process to oxidative stress (Kang et al. 2013). We postulated that gentamicin-induced renal injury was caused by free radical generation with an attenuation of the antioxidant enzymes. Importantly, a marked reduction of renal cortical MDA level accompanied with an improved renal function in pinocembrin plus gentamicin-treated rats might indicate that the ROS was scavenged, and lipid peroxidation was reduced by pinocembrin. However, pinocembrin pretreatment could not restore the decreased activity of SOD enzyme in gentamicin-treated rats. We 
1 hypothesized that pinocembrin might induce other mechanisms to overdrive ROS

2 overproduction.

3 The disruption of Nrf2/Keap1 complex (Keap1 is the regulatory protein of Nrf2)

4 has been activated by oxidative stress and electrophiles (Xing et al. 2012). PKC $\alpha$ was

5 activated by the overproduction of ROS (Arjinajarn et al. 2014; Lee et al. 2003). In this

6 study, Nrf2 was activated in the gentamicin-induced nephrotocixity by the increase of

7 oxidative stress condition indicated by the increased renal PKC $\alpha$ and NOX4

8 expressions. The activation of Nrf2 acts as a cellular adaptive response to stimulate the

9 expression of antioxidant enzymes at specific anti-oxidant response elements (ARE)

10 within the regulatory regions of responsive genes (Itoh et al. 1997; Kobayashi and

11 Yamamoto 2005; Li and Kong 2009) against gentamicin-induced oxidative stress. In the

12 present study, an increased translocation of Nrf2 into the nucleus in the renal cortical

13 tissue of the gentamicin-treated rats could lead to the activation of target genes

14 expression including NQO1 and HO-1. Study in rat kidney cells revealed a protective

15 role of Nrf2 overexpression against triptolide-induced cytotoxicity in a normal rat

16 kidney cells (NRK-52E) through counteracting oxidative stress (Li et al. 2012). Nrf2

17 also protected age-related hearing injuries and gentamicin-induced ototoxicity by up-

18 regulating antioxidant enzymes including NQO1, HO-1, SOD, and GCL and

19 detoxifying proteins (Hoshino et al. 2011). It is noteworthy that pinocembrin

20 pretreatment resulted in a decreased ROS production leading to the inactivation of Nrf2

21 as indicated by a significant reduction in the nuclear translocation of Nrf2. The

22 attenuation of oxidative stress by pinocembrin pretreatment occurred via a decreased

23 Nrf2-mediated transcriptional regulation as well as the NQO1 and HO-1 expressions.

24 The cytoprotective properties of pinocembrin have been shown in chronic cerebral

25 hypoperfusion (Guang and Du 2006) and transient global brain ischemia/reperfusion

26 (Shi et al. 2011) in rats which are associated with reduced oxidative stress. Pinocembrin

27 might act as both direct and indirect antioxidants, via the induction of many

28 cytoprotective proteins, including antioxidant enzymes, and through the inactivation of

29 Nrf2 by superimposing the overproduction of ROS, thus causing the reversal of

30 oxidative stress conditions. There are several studies investigated the protective effects

31 of natural compounds on gentamicin-induced nephrotoxicity. Rosmarinic acid showed 
1 to alleviate gentamicin-induced nephrotoxicity via antioxidant activity, increases of

2 renal GSH content and renal antioxidant enzyme activity (Tavafi and Ahmadvand

3 2011). Recently, curcumin also found to attenuate renal injuries in gentamicin-induced

4 toxicity in rats (He et al. 2015; Manikandan et al. 2011; Negrette-Guzman et al. 2015).

5 Gentamicin-induced apoptosis as shown by the elevated cellular pro-apoptotic

6 (Bax and caspase-3) and reduced anti-apoptotic (Bcl-XL) protein expression was

7 consistent with the histopathological changes in gentamicin-treated rat kidneys in this

8 study. Previously, the increased expressions of apoptotic protein Bax, cytochrome c,

9 cleaved caspase- 9 and cleaved caspase- 3 with a decrease in the expression of anti-

10 apoptotic protein Bcl-2 were observed in renal tubular cells of gentamicin-induced acute

11 kidney injury in rats (Shin et al. 2014). Excessive ROS generated in gentamicin-induced

12 nephrotoxicity is known to cause mitochondrial dysfunction which is an early event in

13 the intrinsic pathway of apoptosis, resulting in morphological and functional changes

14 (Jia et al. 2013; Morales et al. 2010). Pinocembrin provided a renoprotection by

15 inhibiting Bax and caspase-3 overexpressions induced by gentamicin with an enhancing

16 Bcl-XL expression, leading to the alleviation of renal tubular necrosis/damage. It was

17 reported that the anti-apoptotic Bcl-2 family protein could protect the integrity of

18 mitochondrial membrane by binding to the outer membrane of the mitochondria and

19 blocking the efflux of cytochrome c (Kalkan et al. 2012; Kuwana and Newmeyer 2003).

20 The effect of antioxidant treatment on gentamicin-induced apoptosis was reported in

21 both in vivo and in vitro studies (Kang et al. 2013; Ojano-Dirain and Antonelli 2012).

22 Therefore, the beneficial effect of pinocembrin on gentamicin-induced apoptosis in this

23 study could be mediated by the antioxidant effect as the altered expressions of

24 apoptosis-related proteins were preceded by ROS production.

25 In the present study, gentamicin-treated rats showed the decreased renal Oat3

26 function and membrane expression along with an increased PKC $\alpha$ protein expression.

27 The down-regulation of membrane expression of Oat3 was related to the PKC $\alpha$

28 activation by an increase in ROS production (Arjinajarn et al. 2014). Gentamicin

29 treatment might induce the trafficking of Oat3 from the basolateral membrane into the

30 cytoplasm of the proximal tubular cells, resulting in a decreased membrane expression 
1 of Oat 3 and subsequently a decreased renal Oat 3 function. These actions might be

2 associated with the activation of PKC $\alpha$ protein expression through an increased ROS

3 generation by gentamicin treatment. These were supported by the correlation between

4 the decreased membrane expressions of renal Oat1 and Oat 3 and the increasing level of

5 lipid peroxidation in nephrotoxicity rats (Ulu et al. 2012). The restored function and

6 membrane expression of renal Oat3 in gentamicin-treated rats after pinocembrin

7 pretreatment was consistent with the previous study demonstrating that decreased renal

8 Oat1 and Oat3 expressions and functions could be reversed after pretreatment with the

9 antioxidant substance, JBP485 (Cyclo-trans-4-L-hydroxyprolyl-L-serine) (Guo et al.

10 2013). Moreover, treatment with a potent scavenger of free radicals has been reported to

11 prevent the renal toxic effects of gentamicin via the inhibition of a PKC pathway

12 (Parlakpinar et al. 2006). Therefore, the reduction of ROS generation in gentamicin-

13 treated rats by pinocembrin pretreatment might inactivate PKC $\alpha$ which in turn up-

14 regulated the membrane expression of Oat3, leading to improved Oat3 function and

15 finally reversal of renal dysfunction.

\section{Conclusion}

The present results clearly show that pinocembrin can protect gentamicin-

18 induced kidney injury via an amelioration of oxidative stress and apoptosis of renal

19 tissues. It attenuates the increase in oxidative stress and modulates the antioxidant

20 enzymes via the Nrf2/HO-1, NQO1 pathways, thereby leading to reduce protein-related

21 apoptosis results in improved renal Oat3 and kidney functions. Therefore, pinocembrin

22 could be inferred as an alternative therapeutic option to prevent gentamicin-induced

23 nephrotoxicity.

\section{Acknowledgements}

25 We thank Dr. Songkiet Suwansirikul, Department of Pathology, Faculty of

26 Medicine, Chiang Mai University for the valuable suggestions in renal histology. This

27 work was supported by the Thailand Research Fund RSA5780029 (A.L.), and

28 TRG5780019 (P.A.), Thailand and National Research Council of Thailand (Grant 
\#164368;2558A10402068) (A.L.), CMU Mid-Career Research Fellowship program

2 (A.L.), the Faculty of Medicine Research Fund, Chiang Mai University (A.L.), and the

3 NSTDA Research Chair grant from the National Science and Technology Development

4 Agency of Thailand (N.C.).

\section{Conflict of Interest}

The authors have no conflict of interest to disclose.

\section{References}

Abdel-Raheem, I.T., Abdel-Ghany, A.A., and Mohamed, G.A. 2009 Protective effect of quercetin against gentamicin-induced nephrotoxicity in rats. Biol. Pharm. Bull. 32: 61-67. doi: http://doi.org/10.1248/bpb.32.61. PMID: 19122282.

Ajami, M., Eghtesadi, S., Pazoki-Toroudi, H., Habibey, R., and Ebrahimi, S.A. 2010. Effect of crocus sativus on gentamicin induced nephrotoxicity. Biol. Res. 43(1): 83-90. doi: /S0716-97602010000100010. PMID: 21157635.

Arjinajarn, P., Srimaroeng, C., Chatsudthipong, V., and Lungkaphin, A. 2014. Decreased renal organic anion transporter 3 expression in type 1 diabetic rats. Am. J. Med. Sci. 347(3): 221-227. doi: 10.1097/MAJ.0b013e3182831740. PMID: 23470271.

Bankova, V.S., Popov, S.S., and Marekov, N.L. 1982. High-performance liquid chromatographic analysis of flavonoids from propolis. J. Chromatogr. A. 242(1): 135-143. doi: http://dx.doi.org/10.1016/S0021-9673(00)87255-6.

Cao, G., Ying, P., Yan, B., Xue, W., Li, K., Shi, A., Sun, T., Yan, J., and Hu, X. 2015. Pharmacokinetics, safety, and tolerability of single and multiple-doses of pinocembrin injection administered intravenously in healthy subjects. $\mathrm{J}$ Ethnopharmacol. 168: 31-36. doi: 10.1016/j.jep.2015.03.041. PMID: 25814318.

Del Rayo Camacho, M., Sanchez, B., Quiroz, H., Contreras, J.L., and Mata, R. 1991. Pinocembrine: a bioactive flavanone from Teloxys graveolens. J. Ethnopharmacol. 31(3): 383-389. doi: 10.1016/0378-8741(91)90022-6. PMID: 2056764.

Edson, R.S., and Terrell, C.L. 1999. The aminoglycosides. Mayo Clin. Proc. 74(5): 519528. doi: 10.4065/74.5.519. PMID: 10319086.

Gao, M., Zhang, W.C., Liu, Q.S., Hu, J.J., Liu, G.T., and Du, G.H. 2008. Pinocembrin prevents glutamate-induced apoptosis in SH-SY5Y neuronal cells via decrease of bax/bcl-2 ratio. Eur. J. Pharmacol. 591(1-3): 73-79. doi: 10.1016/j.ejphar.2008.06.071. PMID: 18625218.

Guang, H.M., and Du, G.H. 2006. Protections of pinocembrin on brain mitochondria contribute to cognitive improvement in chronic cerebral hypoperfused rats. Eur. J. Pharmacol. 542(1-3): 77-83. doi: 10.1016/j.ejphar.2006.04.054. PMID: 16806158 . 
Guo, X., Meng, Q., Liu, Q., Wang, C., Sun, H., Peng, J., Ma, X., Kaku, T., and Liu, K. 2013. JBP485 improves gentamicin-induced acute renal failure by regulating the expression and function of Oat1 and Oat3 in rats. Toxicol. Appl. Pharmacol. 271(2): 285-295. doi: 10.1016/j.taap.2013.04.029. PMID: 23707770.

He, L., Peng, X., Zhu, J., Liu, G., Chen, X., Tang, C., Liu, H., Liu, F., and Peng, Y. 2015. Protective effects of curcumin on acute gentamicin-induced nephrotoxicity in rats. Can. J. Physiol. Pharmacol. 93(4): 275-282. doi: 10.1139/cjpp-2014-0459. PMID: 25730179.

Hoshino, T., Tabuchi, K., Nishimura, B., Tanaka, S., Nakayama, M., Ishii, T., Warabi, E., Yanagawa, T., Shimizu, R., Yamamoto, M., and Hara, A. 2011. Protective role of Nrf2 in age-related hearing loss and gentamicin ototoxicity. Biochem. Biophys. Res. Commun. 415(1): 94-98. doi: 10.1016/j.bbrc.2011.10.019. PMID: 22020098.

Itoh, K., Chiba, T., Takahashi, S., Ishii, T., Igarashi, K., Katoh, Y., Oyake, T., Hayashi, N., Satoh, K., Hatayama, I., Yamamoto, M., and Nabeshima, Y. 1997. An $\mathrm{Nrf} 2 /$ small Maf heterodimer mediates the induction of phase II detoxifying enzyme genes through antioxidant response elements. Biochem. Biophys. Res. Commun. 236(2): 313-322. doi: 10.1006/bbrc.1997.6943. PMID: 9240432.

Jia, P., Teng, J., Zou, J., Fang, Y., Jiang, S. Yu, X., Kriegel, A.J., Liang, M., and Ding, X. 2013. Intermittent Exposure to Xenon Protects against Gentamicin-Induced Nephrotoxicity. PLoS One 8(5): e64329. doi: 10.1371/journal.pone.0064329. PMID: 23737979

Kalayarasan, S., Prabhu, P.N., Sriram, N., Manikandan, R., Arumugam, M., and Sudhandiran, G. 2009. Diallyl sulfide enhances antioxidants and inhibits inflammation through the activation of $\mathrm{Nrf} 2$ against gentamicin-induced nephrotoxicity in Wistar rats. Eur. J. Pharmacol. 606(1-3): 162-171. doi: 10.1016/j.ejphar.2008.12.055. PMID: 19374873.

Kalkan, Y., Kapakin, K.A., Kara, A., Atabay, T., Karadeniz, A., Simsek, N., Karakus, E., Can, I., Yildirim, S., Ozkanlar, S., and Sengul, E. 2012. Protective effect of Panax ginseng against serum biochemical changes and apoptosis in kidney of rats treated with gentamicin sulphate. J. Mol. Histol. 43(5): 603-613. doi: 10.1007/s10735-012-9412-4. PMID: 22487736.

Kang, C., Lee, H., Hah, D.Y., Heo, J.H., Kim, C.H., Kim, E., and Kim, J.S. 2013. Protective Effects of Houttuynia cordata Thunb. on Gentamicin-induced Oxidative Stress and Nephrotoxicity in Rats. Toxicol. Res. 29(1): 61-67. doi: 10.5487/tr.2013.29.1.061. PMID: 24278630.

Karahan, I., Atessahin, A., Yilmaz, S., Ceribasi, A.O., and Sakin, F. 2005. Protective effect of lycopene on gentamicin-induced oxidative stress and nephrotoxicity in rats. Toxicology 215(3): 198-204. doi: 10.1016/j.tox.2005.07.007. PMID: 16125832.

Kobayashi, M., and Yamamoto, M. 2005. Molecular mechanisms activating the Nrf2Keap1 pathway of antioxidant gene regulation. Antioxid. Redox. Signal. 7(3-4): 385-394. doi: 10.1089/ars.2005.7.385. PMID: 15706085.

Koepsell, H. 2013. The SLC22 family with transporters of organic cations, anions and zwitterions. Mol. Aspects Med. 34(2-3): 413-435. doi: 10.1016/j.mam.2012.10.010. PMID: 23506881. 
Kuwana, T., and Newmeyer, D.D. 2003. Bcl-2-family proteins and the role of mitochondria in apoptosis. Curr. Opin. Cell Biol. 15(6): 691-699. doi: 10.1016/j.ceb.2003.10.004. PMID: 14644193.

Lee, H.B., Yu, M.R., Yang, Y., Jiang, Z., and Ha, H. 2003. Reactive oxygen speciesregulated signaling pathways in diabetic nephropathy. J. Am. Soc. Nephrol. 14(8 Suppl 3): S241-245. doi: 10.1097/01.ASN.0000077410.66390.0F. PMID: 12874439.

Li, J., Jin, J., Li, M., Guan, C., Wang, W., Zhu, S., Qiu, Y., Huang, M., and Huang, Z. 2012. Role of Nrf2 in protection against triptolide-induced toxicity in rat kidney cells. Toxicol. Lett. 213(2): 194-202. doi: 10.1016/j.toxlet.2012.07.008. PMID: 22820427.

Li, W., and Kong, A.N. 2009. Molecular mechanisms of Nrf2-mediated antioxidant response. Mol. Carcinog. 48(2): 91-104. doi: 10.1002/mc.20465. PMID: 18618599.

Lopez-Novoa, J.M., Quiros, Y., Vicente, L., Morales, A.I., and Lopez-Hernandez, F.J. 2011. New insights into the mechanism of aminoglycoside nephrotoxicity: an integrative point of view. Kidney Int. 79(1): 33-45. doi: 10.1038/ki.2010.337. PMID: 20861826.

Lungkaphin, A., Arjinajarn, P., Pongchaidecha, A., Srimaroeng, C., Chatsudthipong, L., and Chatsudthipong, V. 2014. Impaired insulin signaling affects renal organic anion transporter 3 (Oat3) function in streptozotocin-induced diabetic rats. PLoS One 9(5): e96236. doi: 10.1371/journal.pone.0096236. PMID: 24801871.

Lungkaphin, A., Pongchaidecha, A., Palee, S., Arjinajarn, P., Pompimon, W., and Chattipakorn, N. 2015. Pinocembrin reduces cardiac arrhythmia and infarct size in rats subjected to acute myocardial ischemia/reperfusion. Appl. Physiol. Nutr. Metab. 40(10): 1031-1037. doi: 10.1139/apnm-2015-0108. PMID: 26319563.

Manikandan, R., Beulaja, M., Thiagarajan, R., Priyadarsini, A., Saravanan, R., and Arumugam, M. 2011. Ameliorative effects of curcumin against renal injuries mediated by inducible nitric oxide synthase and nuclear factor kappa B during gentamicin-induced toxicity in Wistar rats. Eur. J. Pharmacol. 670(2-3): 578585. doi: 10.1016/j.ejphar.2011.08.037. PMID: 21925163.

Mazzon, E., Britti, D., De Sarro, A., Caputi, A.P., and Cuzzocrea, S. 2001. Effect of Nacetylcysteine on gentamicin-mediated nephropathy in rats. Eur. J. Pharmacol. 424(1): 75-83. doi: 10.1016/S0014-2999(01)01130-X. PMID: 11470263.

Morales, A.I., Detaille, D., Prieto, M., Puente, A., Briones, E., Arevalo, M., Leverve, X., Lopez-Novoa, J.M., and El-Mir, M.Y. 2010. Metformin prevents experimental gentamicin-induced nephropathy by a mitochondria-dependent pathway. Kidney Int. 77(10): 861-869. doi: 10.1038/ki.2010.11. PMID: 20164825.

Nagai, J., and Takano, M. 2004. Molecular aspects of renal handling of aminoglycosides and strategies for preventing the nephrotoxicity. Drug Metab. Pharmacokinet. 19(3): 159-170. doi: 10.2133/dmpk.19.159. PMID: 15499183.

Nasri, H., Nematbakhsh, M., and Rafieian-Kopaei, M. 2013. Ethanolic extract of garlic for attenuation of gentamicin-induced nephrotoxicity in Wistar rats. Iran J. Kidney Dis. 7(5): 376-382. PMID: 24072150. 
Negrette-Guzman, M., Garcia-Nino, W.R., Tapia, E., Zazueta, C., Huerta-Yepez, S., Leon-Contreras, J.C., Hernandez-Pando, R., Aparicio-Trejo, O.E., Madero, M., and Pedraza-Chaverri, J. 2015. Curcumin Attenuates Gentamicin-Induced Kidney Mitochondrial Alterations: Possible Role of a Mitochondrial Biogenesis Mechanism. Evid. Based Complement. Alternat. Med. 2015: 917435. doi: 10.1155/2015/917435. PMID: 26345660.

Noone, P., Parsons, T.M., Pattison, J.R., Slack, R.C., Garfield-Davies, D., and Hughes, K. 1974. Experience in monitoring gentamicin therapy during treatment of serious gram-negative sepsis. Br. Med. J. 1(5906): 477-481. doi: http://dx.doi.org/10.1136/bmj.1.5906.477. PMID: 4206128.

Ohkawa, H., Ohishi, N., and Yagi, K. 1979. Assay for lipid peroxides in animal tissues by thiobarbituric acid reaction. Anal. Biochem. 95(2): 351-358. doi: 10.1016/0003-2697(79)90738-3. PMID: 36810.

Ojano-Dirain, C.P., and Antonelli, P.J. 2012. Prevention of gentamicin-induced apoptosis with the mitochondria-targeted antioxidant mitoquinone. Laryngoscope 122(11): 2543-2548. doi: 10.1002/lary.23593. PMID: 22965463.

Parlakpinar, H., Tasdemir, S., Polat, A., Bay-Karabulut, A., Vardi, N., Ucar, M., Yanilmaz, M., Kavakli, A., and Acet, A. 2006. Protective effect of chelerythrine on gentamicin-induced nephrotoxicity. Cell Biochem. Funct. 24(1): 41-48. doi: 10.1002/cbf.1182. PMID: 15584091.

Pepeljnjak, S., Jalsenjak, I., and Maysinger, D. 1985. Flavonoid content in propolis extracts and growth inhibition of Bacillus subtilis. Pharmazie 40(2): 122-123. PMID: 3923500.

Punvittayagul, C., Wongpoomchai, R., Taya, S., and Pompimon, W. 2011. Effect of pinocembrin isolated from Boesenbergia pandurata on xenobiotic-metabolizing enzymes in rat liver. Drug Metab. Lett. 5(1): 1-5. doi: http://dx.doi.org/10.2174/187231211794455226. PMID: 20942797.

Rizzi M.D., and Hirose, K. 2007. Aminoglycoside ototoxicity. Curr. Opin. Otolaryngol. Head Neck Surg. 15(5): 352-357. PMID: 17823553

Sahu, B.D., Kuncha, M., Sindhura, G.J., and Sistla, R. 2013. Hesperidin attenuates cisplatin-induced acute renal injury by decreasing oxidative stress, inflammation and DNA damage. Phytomedicine 20(5): 453-460. doi: http://dx.doi.org/10.1016/j.phymed.2012.12.001. PMID: 23353054.

Sala, A., Recio, M.C., Schinella, G.R., Manez, S., Giner, R.M., Cerda-Nicolas, M., and Rosi, J.L. 2003. Assessment of the anti-inflammatory activity and free radical scavenger activity of tiliroside. Eur. J. Pharmacol. 461(1): 53-61. doi: 10.1016/S0014-2999(02)02953-9. PMID: 12568916.

Santos, A.C., Uyemura, S.A., Lopes, J.L., Bazon, J.N., Mingatto, F.E., and Curti, C. 1998. Effect of naturally occurring flavonoids on lipid peroxidation and membrane permeability transition in mitochondria. Free Radic. Biol. Med. 24(9): 1455-1461. doi: 10.1016/S0891-5849(98)00003-3. PMID: 9641263.

Sekine, T., Cha, S.H., and Endou, H. 2000. The multispecific organic anion transporter (OAT) family. Pflugers Arch. 440(3): 337-350. doi: 10.1007/s004240000297. PMID: 10954321.

Shi, L.L., Chen, B.N., Gao, M., Zhang, H.A., Li, Y.J., Wang, L., and Du, G.H. 2011. The characteristics of therapeutic effect of pinocembrin in transient global brain 
ischemia/reperfusion rats. Life Sci. 88(11-12): 521-528. doi: 10.1016/j.lfs.2011.01.011. PMID: 21262238.

Shin, H.S., Yu, M., Kim, M., Choi, H.S., and Kang, D.H. 2014. Renoprotective effect of red ginseng in gentamicin-induced acute kidney injury. Lab. Invest. 94(10): 1147-1160. doi: 10.1038/labinvest.2014.101. PMID: 25111692.

Soromou, L.W., Chu, X., Jiang, L., Wei, M., Huo, M., Chen, N., Guan, S., Yang, X., Chen, C., Feng, H., and Deng, X. 2012. In vitro and in vivo protection provided by pinocembrin against lipopolysaccharide-induced inflammatory responses. Int. Immunopharmacol. 14(1): 66-74. doi: 10.1016/j.intimp.2012.06.009. PMID: 22713932.

Tavafi, M., and Ahmadvand, H. 2011. Effect of rosmarinic acid on inhibition of gentamicin induced nephrotoxicity in rats. Tissue Cell 43(6): 392-397. doi: 10.1016/j.tice.2011.09.001. PMID: 22000907.

Ulu, R., Dogukan, A., Tuzcu, M., Gencoglu, H., Ulas, M., Ilhan, N., Muqbil, I., Mohammad, R.M., Kucuk, O., and Sahin, K. 2012. Regulation of renal organic anion and cation transporters by thymoquinone in cisplatin induced kidney injury. Food Chem. Toxicol. 50(5): 1675-1679. doi: 10.1016/j.fct.2012.02.082. PMID: 22414646.

Walker, P.D., Barri, Y., and Shah, S.V. 1999. Oxidant mechanisms in gentamicin nephrotoxicity. Ren. Fail. 21(3-4): 433-442. doi: 10.3109/08860229909085109. PMID: 10416224.

Walker, P.D., and Shah, S.V. 1987. Gentamicin enhanced production of hydrogen peroxide by renal cortical mitochondria. Am. J. Physiol. 253(4 Pt 1): C495-499. PMID: 3661692.

Xing, X., Zhang, C., Shao, M., Tong, Q., Zhang, G., Li, C., Cheng, J., Jin, S., Ma, J., Wang, G., Li, X., and Cai, L. 2012. Low-dose radiation activates Akt and Nrf2 in the kidney of diabetic mice: a potential mechanism to prevent diabetic nephropathy. Oxid. Med. Cell Longev. 2012: 291087. doi: 10.1155/2012/291087. PMID: 23227273.

Yang, C.L., Du, X.H., and Han, Y.X. 1995. Renal cortical mitochondria are the source of oxygen free radicals enhanced by gentamicin. Ren. Fail. 17(1): 21-26. doi: 10.3109/08860229509036371. PMID: 7770640. 
Table 1 Effects of pinocembrin pre-treatment on physiological and renal function parameters in gentamicin-treated rats

\begin{tabular}{|c|c|c|c|c|c|}
\hline Parameter & Control & $\begin{array}{c}\text { Gentamicin } \\
100 \mathrm{mg} / \mathrm{kg}\end{array}$ & $\begin{array}{c}\text { Gentamicin } \\
100 \mathrm{mg} / \mathrm{kg} \\
+ \text { pinocembrin } \\
50 \mathrm{mg} / \mathrm{kg}\end{array}$ & $\begin{array}{c}\text { Gentamicin } \\
100 \mathrm{mg} / \mathrm{kg} \\
+ \text { pinocembrin } \\
75 \mathrm{mg} / \mathrm{kg}\end{array}$ & $\begin{array}{l}\text { Pinocembrin } \\
50 \mathrm{mg} / \mathrm{kg}\end{array}$ \\
\hline Body weight (g) & $337 \pm 7.95$ & $294 \pm 8.13^{*}$ & $308 \pm 2.50^{\#}$ & $323 \pm 3.30^{\#}$ & $324 \pm 7.50$ \\
\hline Kidney weight (g) & $1.33 \pm 0.02$ & $2.00 \pm 0.16^{*}$ & $1.50 \pm 0.03^{\#}$ & $1.47 \pm 0.06^{\#}$ & $1.32 \pm 0.02$ \\
\hline KW/BW ratio & $0.004 \pm 0.0001$ & $0.006 \pm 0.0003^{*}$ & $0.005 \pm 0.0001^{\#}$ & $0.004 \pm 0.0002^{\#}$ & $0.004 \pm 0.0001$ \\
\hline \multicolumn{6}{|l|}{ Renal function } \\
\hline Serum BUN (mg\%) & $21.50 \pm 0.76$ & $31.16 \pm 1.83^{*}$ & $26.33 \pm 1.80^{\#}$ & $23.33 \pm 0.88^{\#}$ & $21.40 \pm 0.68$ \\
\hline Serum Cr (mg\%) & $0.47 \pm 0.02$ & $0.73 \pm 0.04^{*}$ & $0.58 \pm 0.03^{\#}$ & $0.55 \pm 0.07^{\#}$ & $0.37 \pm 0.04$ \\
\hline $\mathrm{C}_{\mathrm{cr}}(\mathrm{ml} / \mathrm{min})$ & $2.07 \pm 0.11$ & $1.17 \pm 0.07^{*}$ & $1.35 \pm 0.08^{\#}$ & $1.51 \pm 0.36^{\#}$ & $2.40 \pm 0.16$ \\
\hline
\end{tabular}

Values are mean $\pm \mathrm{SE}$; ( $\mathrm{n}=6$ rats in each group). GM, gentamicin; KW/BW ratio, kidney weight/bodyweight ratio; BUN, blood urea nitrogen; creatinine, $\mathrm{Cr}$; creatinine clearance, $\mathrm{C}_{\mathrm{cr}}{ }^{*} P<0.05$ compared with control; ${ }^{\sharp} P<0.05$ compared with gentamicin-treated rats. 


\section{Figure legends}

2 Figure 1 Effects of pinocembrin pretreatment on $\left[{ }^{3} \mathrm{H}\right] \mathrm{ES}$ uptake in renal cortical slices.

3 Renal cortical slices were incubated in buffer containing $50 \mathrm{nM}\left[{ }^{3} \mathrm{H}\right] \mathrm{ES}$ for 30 minutes

4 at room temperature. The uptake was calculated as tissue/medium ratio and then

5 converted to a mean percentage of the control. Values are expressed as the mean \pm SEM

6 from six rats ( 5 slices/group/animal). ${ }^{*} P<0.05$ compared to the control group, ${ }^{\#} P<$

70.05 compared to the gentamicin-treated group.

8 Figure 2 Effects of pinocembrin pretreatment on Oat3 expression in the renal cortical

9 tissue. A: Western blot analysis of Oat3 in the membrane and B: in the whole cell lysate

10 fractions of renal cortical tissues. The signal intensity of Oat 3 in membrane and whole

11 cell lysate fractions normalized to $\beta$-actin. Bar graphs indicate mean \pm SEM (from 6 rats

12 in each group). ${ }^{*} P<0.05$ compared to the control group, ${ }^{\#} P<0.05$ compared to the

13 gentamicin-treated group.

14 Figure 3 A. Effects of pinocembrin pretreatment on the renal cortical MDA

15 concentration. Thiobarbituric acid reactive substances (TBARS) were measured in renal

16 cortical tissues. B. Effects of pinocembrin pretreatment on SOD enzyme activity in

17 renal cortical tissue. Values are the mean \pm SEM. ( $n=6$ rats in each group). ${ }^{*} P<0.05$

18 compared to the control, ${ }^{\#} P<0.05$ compared to the gentamicin-treated group.

19 Figure 4 Effects of pinocembrin pretreatment on the expressions of $\mathrm{PKC} \alpha(\mathrm{A})$ and

$20 \mathrm{NOX} 4$ (B) in renal cortical tissues. Immunoblot analysis for PKC $\alpha$ and NOX4

21 expressions in whole cell lysate fraction of renal cortical tissue and immunostaining

22 signal intensity of PKC $\alpha$ and NOX4 expressions normalized to $\beta$-actin. Bar graphs

23 indicate mean \pm SEM ( $\mathrm{n}=6$ rats in each group). ${ }^{*} P<0.05$ compared to the control, ${ }^{\#} P<$

240.05 compared to the gentamicin-treated group.

25 Figure 5 Effects of pinocembrin pretreatment on the expression of $\mathrm{Nrf} 2$ in the renal 26 cortical tissue. Immunoblot analysis for Nrf2 in nuclear (A) Nrf2 in cytosolic fractions

27 (B) HO-1 (C) and NQO1 (D) expressions of renal cortical tissues. Immunostaining 28 signal intensity protein expressions normalized to $\beta$-actin. Bar graphs indicate mean \pm 
1 SEM ( $\mathrm{n}=6$ rats in each group). ${ }^{*} P<0.05$ compared to the control, ${ }^{\#} P<0.05$ compared 2 to the gentamicin-treated group.

3 Figure 6 Effects of pinocembrin pretreatment on the expression of apoptotic proteins in 4 renal cortical tissue. (A), (B) and (D): Representative immunoblot analysis for Bax, Bcl-

$5 \mathrm{XL}$ and caspase-3 expressions in renal cortical tissues, respectively. (C):

6 Immunostaining signal intensities of Bax/Bcl-XL ratio. Immunostaining signal

7 intensities of Bax, Bcl-XL and caspase-3 expressions normalized to $\beta$-actin. Bar graphs

8 indicate mean \pm SEM ( $\mathrm{n}=6$ rats in each group). ${ }^{*} P<0.05$ compared to the control, ${ }^{\#} P<$

90.05 compared to the gentamicin-treated group.

10 Figure 7 Hematoxylin and eosin (H\&E) stain of the kidneys (magnification, $x 40)$.

11 Panels A, B, C and D are images of glomeruli and renal tubules from control (A),

12 gentamicin (B), gentamicin + pinocembrin (C) and pinocembrin rats (D), respectively.

13 The mitosis and tubular detachment (B) in gentamicin kidney are shown with

14 arrowheads and black arrows, respectively. 


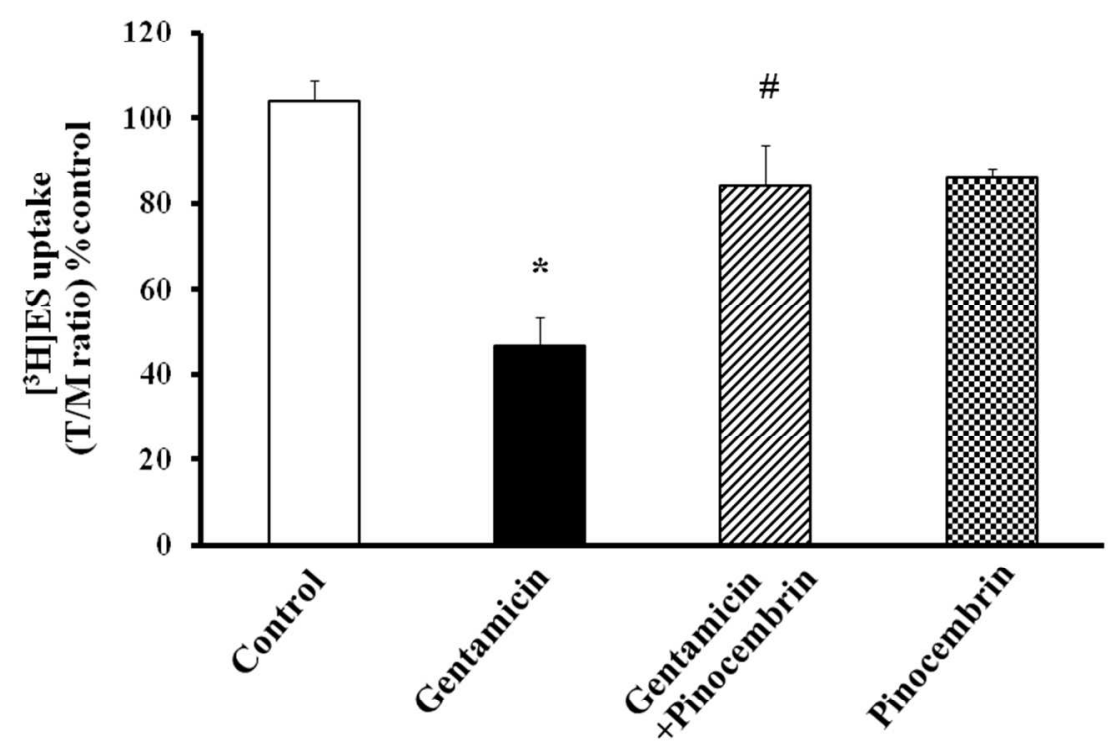

Figure 1 Effects of pinocembrin pretreatment on [3H]ES uptake in renal cortical slices. Renal cortical slices were incubated in buffer containing $50 \mathrm{nM}$ [3H]ES for 30 minutes at room temperature. The uptake was calculated as tissue/medium ratio and then converted to a mean percentage of the control. Values are expressed as the mean \pm SEM from six rats ( 5 slices/group/animal). $* P<0.05$ compared to the control group, \#P $<0.05$ compared to the gentamicin-treated group. $420 \times 297 \mathrm{~mm}(300 \times 300 \mathrm{DPI})$ 
A. Membrane fractions
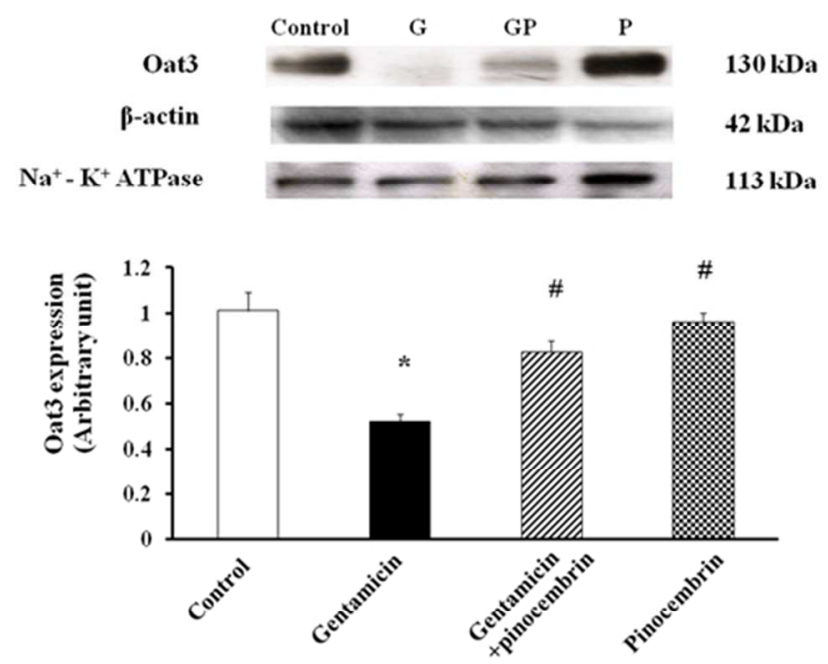

B.

Whole cell lysate fractions

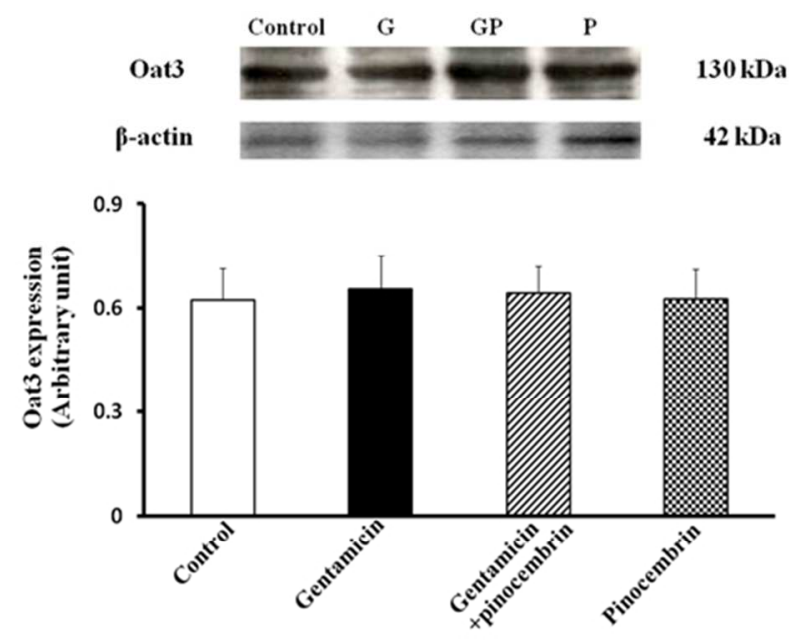

Figure 2 Effects of pinocembrin pretreatment on Oat3 expression in the renal cortical tissue. A: Western blot analysis of Oat3 in the membrane and B: in the whole cell lysate fractions of renal cortical tissues. The signal intensity of Oat3 in membrane and whole cell lysate fractions normalized to $\beta$-actin. Bar graphs indicate mean \pm SEM (from 6 rats in each group). ${ }^{*} \mathrm{P}<0.05$ compared to the control group, $\# \mathrm{P}<0.05$ compared to the gentamicin-treated group. $60 \times 81 \mathrm{~mm}(300 \times 300 \mathrm{DPI})$ 


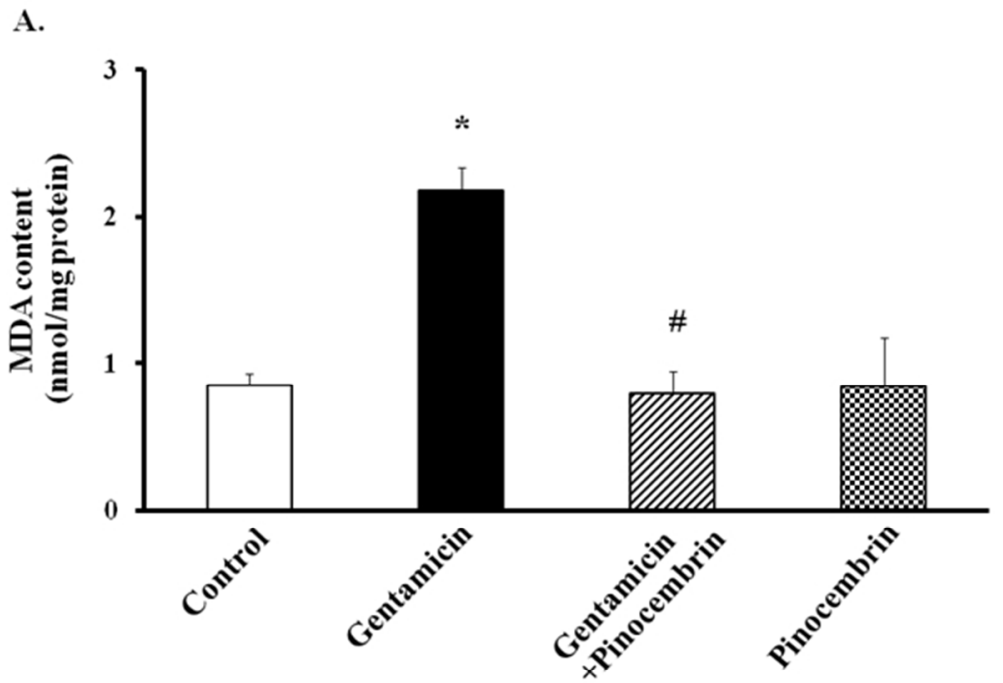

B.

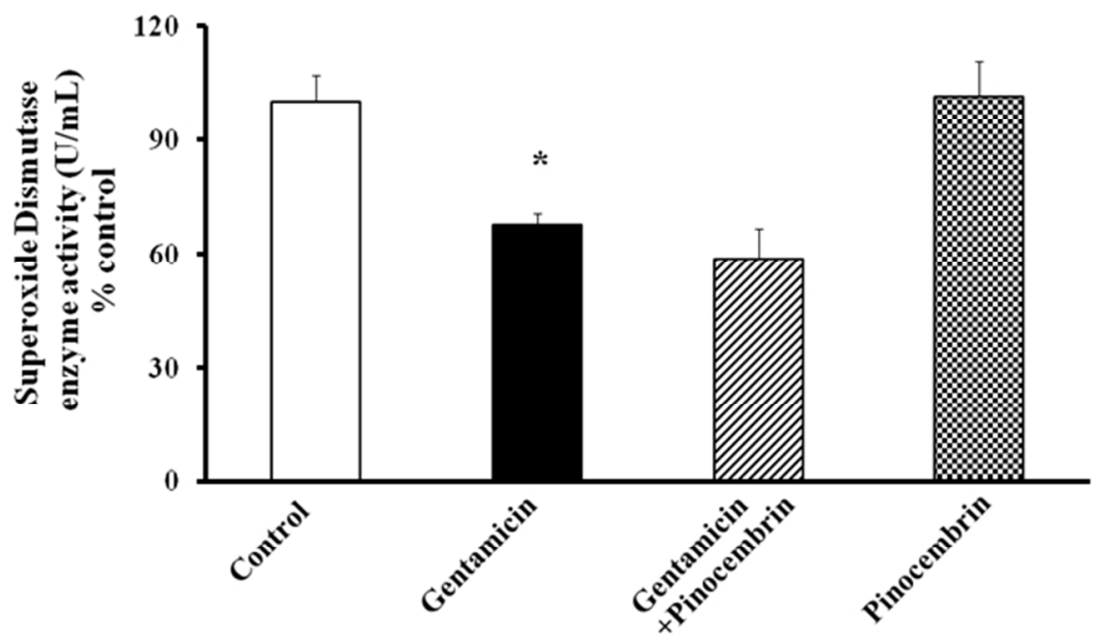

Figure $3 \mathrm{~A}$. Effects of pinocembrin pretreatment on the renal cortical MDA concentration. Thiobarbituric acid reactive substances (TBARS) were measured in renal cortical tissues. B. Effects of pinocembrin pretreatment on SOD enzyme activity in renal cortical tissue. Values are the mean \pm SEM. ( $n=6$ rats in each group). $* P<$ 0.05 compared to the control, \#P $<0.05$ compared to the gentamicin-treated group. $60 \times 81 \mathrm{~mm}(300 \times 300$ DPI $)$ 
A.

Whole cell lysate fractions

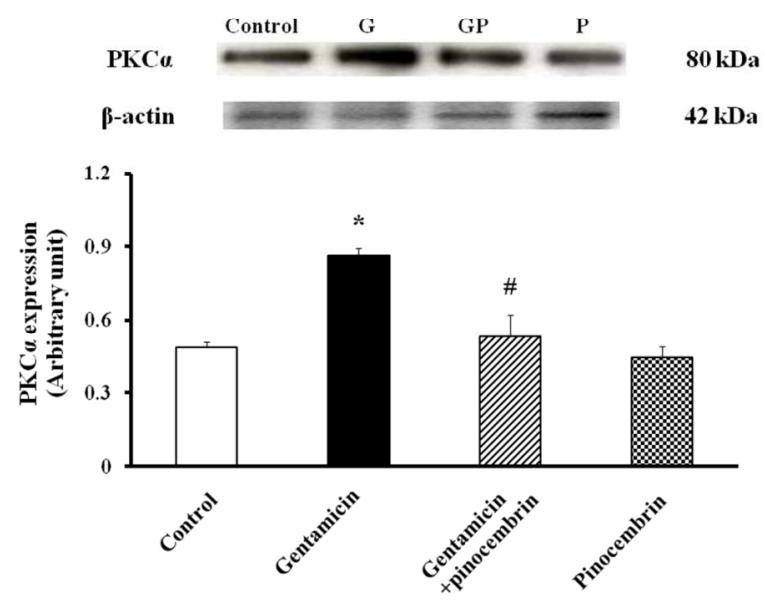

B.

Whole cell lysate fractions

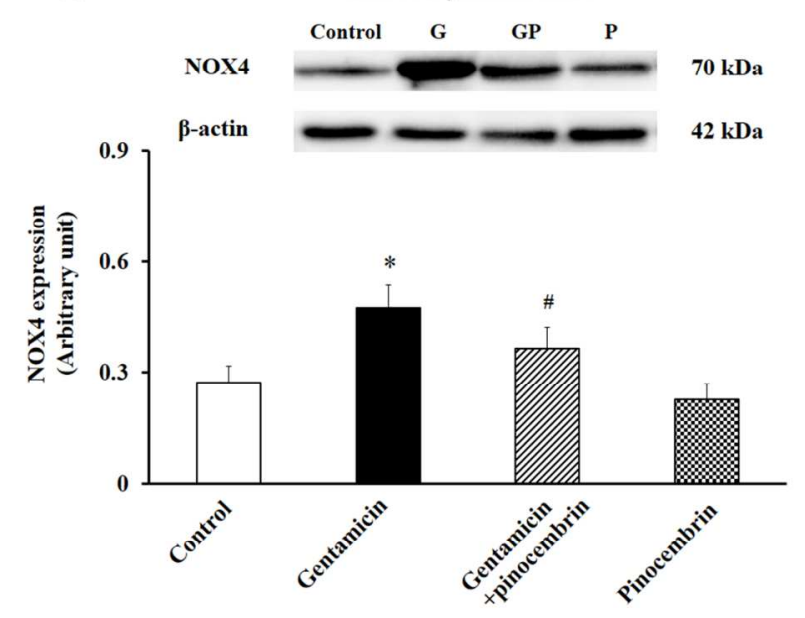

Figure 4 Effects of pinocembrin pretreatment on the expressions of PKCa (A) and NOX4 (B) in renal cortical tissues. Immunoblot analysis for PKCa and NOX4 expressions in whole cell lysate fraction of renal cortical tissue and immunostaining signal intensity of PKCa and NOX4 expressions normalized to $\beta$-actin. Bar graphs indicate mean \pm SEM ( $n=6$ rats in each group). $* P<0.05$ compared to the control, \#P<0.05 compared to the gentamicin-treated group. $209 \times 297 \mathrm{~mm}(300 \times 300$ DPI $)$ 
A.

Cytosol fractions

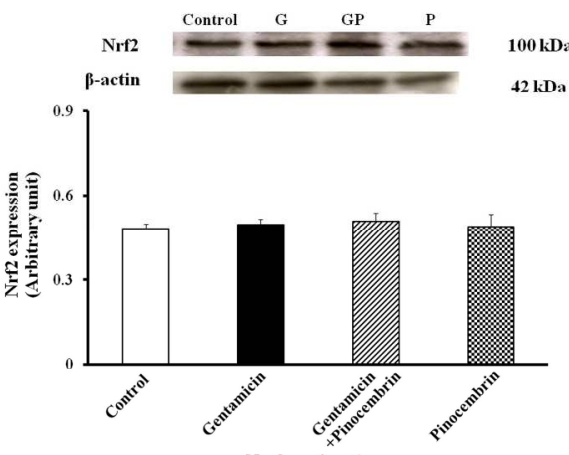

B.

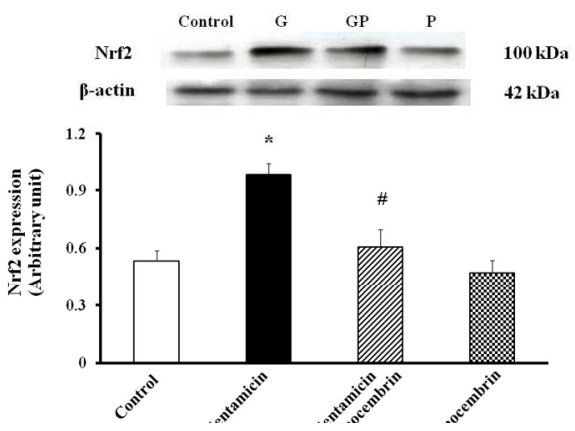

C.

Whole cell lysate fractions
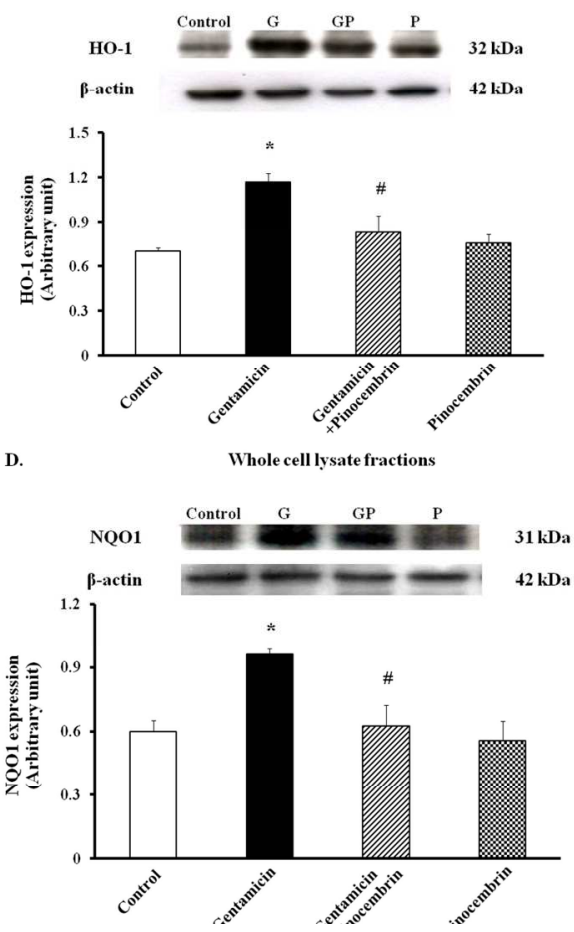

Figure 5 Effects of pinocembrin pretreatment on the expression of Nrf2 in the renal cortical tissue. Immunoblot analysis for Nrf2 in nuclear (A) Nrf2 in cytosolic fractions (B) HO-1 (C) and NQO1 (D) expressions of renal cortical tissues. Immunostaining signal intensity protein expressions normalized to $\beta$ actin. Bar graphs indicate mean $\pm \operatorname{SEM}(n=6$ rats in each group). $* P<0.05$ compared to the control, \#P $<$ 0.05 compared to the gentamicin-treated group. $260 \times 194 \mathrm{~mm}(300 \times 300 \mathrm{DPI})$ 


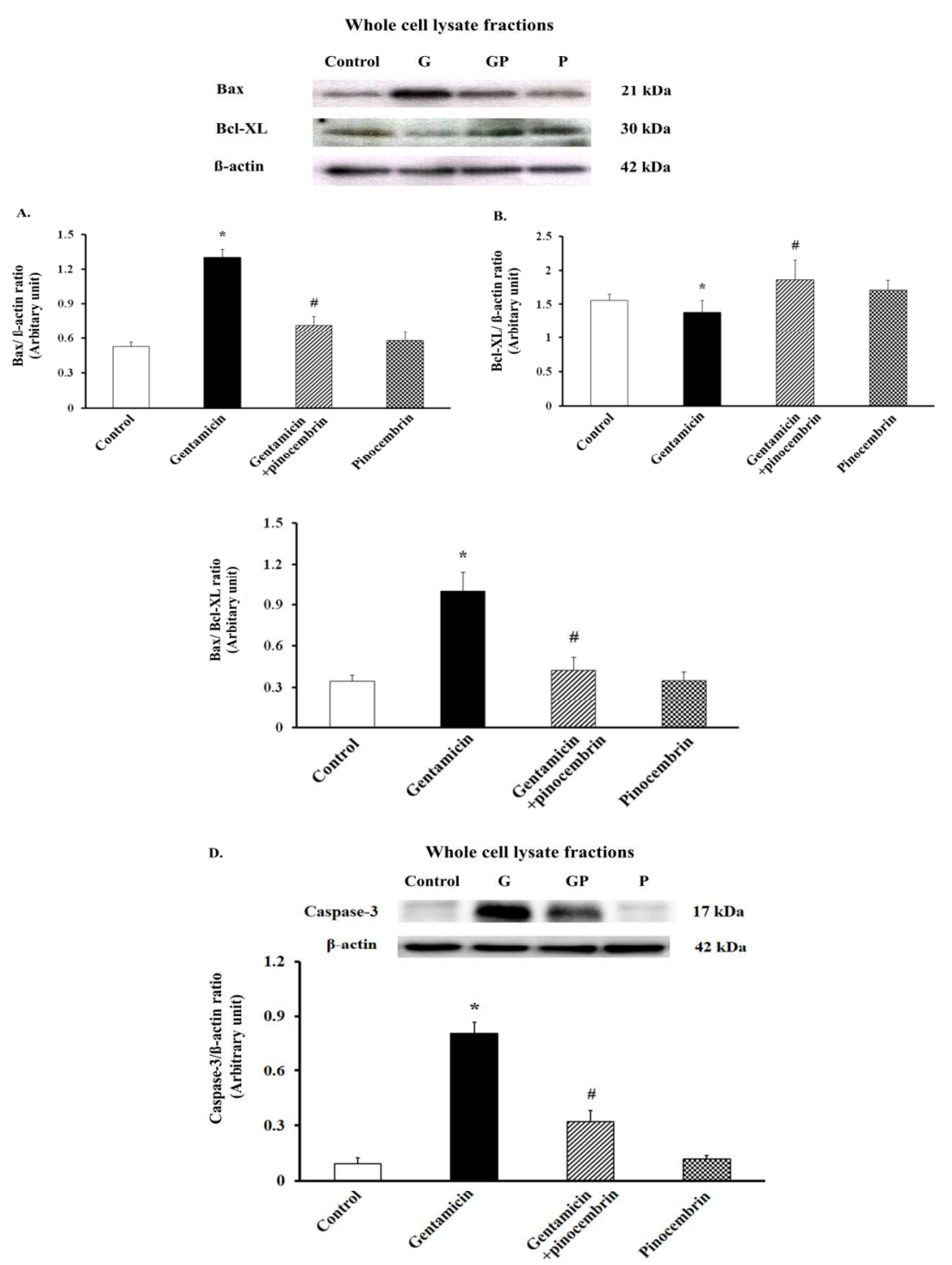

Figure 6 Effects of pinocembrin pretreatment on the expression of apoptotic proteins in renal cortical tissue. (A), (B) and (D): Representative immunoblot analysis for Bax, BCl-XL and caspase-3 expressions in renal cortical tissues, respectively. (C): Immunostaining signal intensities of Bax/Bcl-XL ratio. Immunostaining signal intensities of Bax, Bcl-XL and caspase- 3 expressions normalized to $\beta$-actin. Bar graphs indicate mean $\pm \operatorname{SEM}\left(\mathrm{n}=6\right.$ rats in each group). ${ }^{*} \mathrm{P}<0.05$ compared to the control, $\# \mathrm{P}<0.05$ compared to the gentamicintreated group.

$304 \times 381 \mathrm{~mm}(300 \times 300$ DPI $)$ 


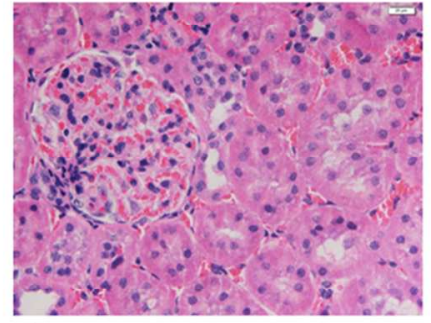

A

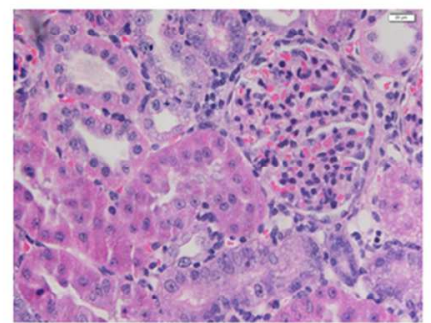

C

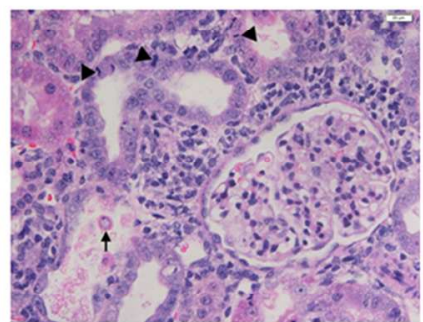

B

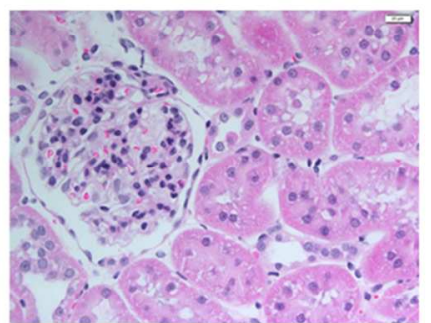

D

Figure 7 Hematoxylin and eosin (H\&E) stain of the kidneys (magnification, $x 40$ ). Panels A, B, C and D are images of glomeruli and renal tubules from control (A), gentamicin (B), gentamicin + pinocembrin (C) and pinocembrin rats (D), respectively. The mitosis and tubular detachment $(B)$ in gentamicin kidney are shown with arrowheads and black arrows, respectively.

$420 \times 297 \mathrm{~mm}(300 \times 300 \mathrm{DPI})$ 